\title{
NOTAS SOBRE LAS TECHUMBRES MUDÉJARES TUROLENSES ${ }^{1}$
}

\author{
Beatriz Rubio Torrero
}

En la medida en que la incipiente labor de investigación que he realizado me lo permite, en este artículo voy a dar unas breves noticias sobre las techumbres mudéjares turolenses, apuntando sus tipologías y las relaciones que mantienen con otras obras peninsulares. Desde luego, las obras que aquí cito hay que contextualizarlas en el conjunto del arte mudéjar aragonés para poder valorarlas adecuadamente. En este sentido, es obligado mencionar los estudios de Gonzalo Borrás sobre el tema, que sirven de importante referencia; hay que señalar que este investigador se ha ocupado también del estudio de las obras de carpintería mudéjar y en sus obras se pueden hallar estudios de conjunto sobre las techumbres mudéjares aragonesas ${ }^{2}$.

La tarea de realizar un estudio científico completo sobre este tema, en el que las obras artísticas puedan situarse en una coherente evolución estructural y decorativa, plantea algunas dificultades. Muchas techumbres de madera han desaparecido debido a la fragilidad del material con que se construyeron, otras se sustituyeron por cubiertas más modernas. Los problemas aumentan si a ello añadimos que algunas obras fueron compradas por coleccionistas extranjeros y enviadas fuera de España, en unas circunstancias que no facilitan situar concretamente su lugar de procedencia.

Para evitar repetir lo que otros investigadores han estudiado sobre las obras localizadas en el extranjero y a las que no he accedido, no insistiré en

1. En 1992 el Instituto de Estudios Turolenses me concedió una Ayuda a la Investigación para realizar el trabajo titulado "Inventario y catalogación de las techumbres mudéjares turolenses $^{\prime \prime}$, inédito. El artículo que presento a continuación es un resumen de ese trabajo. Agradezco desde aquí a María Isabel Alvaro, Ernesto Arce, Bernabé Cabañero y Oscar Rillo la ayuda que me prestaron; igualmente agradezco la amabilidad de los párrocos de las iglesias y ermitas que visité, así como la disponibilidad del Instituto de Estudios Turolenses en todo momento.

2. Cfr. Gonzalo Borrás, Arte mudéjar aragonés, Zaragoza, 1978; id., Arte mudéjar aragonés (III tomos), Zaragoza, 1985; id., El arte mudéjar en Ternel y su provincia, Teruel, 1987; id., El arte mudéjar, Teruel, 1990. Las techumbres aragonesas que cito a lo largo de este artículo pueden localizarse en el tomo II del segundo trabajo citado. 
ellas; me refiero concretamente a las techumbres de Villa Schifanoia, de la colección Hearst y de la colección Steedman ${ }^{3}$.

Pero sin duda la techumbre más estudiada de todas las turolenses y aragonesas es la de la Catedral de Teruel, e incluso una de las que más ha llamado la atención de los investigadores a nivel nacional, casi siempre para referirse a la pintura gótica figurativa que la decora y su estudio iconográfico. Pero no hay que olvidar que, como ya han puesto de relieve Gonzalo Borrás y Joaquín Yarza ${ }^{4}$, la organización decorativa a base de campos ornamentales de esta armadura, unida claramente a su concepción estructural, está dentro de la tradición islámica, así como también muchos de sus motivos decorativos. Considero inoportuno tanto describir esta techumbre como profundizar en el tema, incluido el de la cronología, ya que creo que está prácticamente claro que hay que datarla en el último tercio del siglo XIII ${ }^{5}$.

No obstante, me gustaría comentar que se trata de la única techumbre de par y nudillo aragonesa conocida, por lo que suele considerarse como una importación a territorio turolense ${ }^{6}$. Quizás la escasa fortuna de estas estructuras de tradición almohade en territorio aragonés sea debida a la difusión de las cubiertas sobre arcos diafragma para cubrir estancias a dos aguas; este sistema es menos arriesgado por precisar de vigas de menor escuadría y lon-

3. Los artículos que tratan estas techumbres con mayor profundidad son los siguientes: Santiago SEBASTIÁN, «Techos turolenses emigrados», Teruel, $\mathbf{n}^{\circ}$ 22, 1959, pp. 217-224; Ursula TRENTA, «Estudio sobre un artesonado turolense existente en Italia», Teruel, $\mathrm{n}^{\circ}$ 35, 1966, pp. 101-130; José Miguel Merino, «El techo de la 'Casa del Judío' en Norteamérica», Aragón Cultural, segunda época, marzo 1987, $\mathrm{n}^{\circ}$ 5, pp. 101-108. Pedro José LAVADo niega el carácter turolense de la techumbre de la colección Steedman en Santa Bárbara, ya que para él se trata de un fragmento de la techumbre de la iglesia de San Nicolás de Sinovas en Burgos; véase su artículo "Repercusión e influencias iconográficas de la techumbre mudéjar de la catedral de Teruel», Actas III Coloquio de Arte Aragonés. Huesca, 19-21 diciembre 1983. Sección II, Huesca, 1985, pp. 191-199.

4. Entre los estudios sobre la techumbre de la Catedral de Teruel hay que destacar los siguientes: Angel Novel LA, «El artesonado de la Catedral de Teruel. (Santa María de Mediavilla)», Teruel, $n^{\circ}$ 32, 1964, pp. 175-233; Joaquín YARZA, «Santa María de Mediavilla, Teruel: pintura de la techumbre mudéjar», en Teruel Mudéjar: Patrimonio de la Humanidad, Zaragoza, 1991, pp. 239-318; Gonzalo BORRÁs, El arte mudéjar en Teruel..., pp. 24-36. Conviene también citạr, debido a la cantidad de ilustraciones que recoge, el libro de VV.AA., El artesonado de la Catedral de Teruel, Zaragoza, 1981.

5. Un análisis dendrocronológico realizado por Rodríguez Trobajo sobre varias maderas de la techumbre ha arrojado la fecha de 1261 para la tala de los árboles que sirvieron para su construcción, fecha que viene a apoyar la cronología que desde hace años se le venía adscribiendo. Véase Antonio Almagro, «Arquitectura mudéjar en Teruel», en Teruel Mudéjar: Patrimonio de la Humanidad, Zaragoza, 1991, p. 190.

6. En la zona de Albarracín, próxima a Teruel, se localiza una techumbre de par y nudillo, ochavada en la cabecera, en la ermita conocida como El Torrejón; se trata de una obra tardía, probablemente del siglo XVI, y que en mi opinión habría que relacionar más con la posible influencia de obras castellanas que con la de la techumbre de la catedral de Teruel. Véase Antonio Almagro, Urbanismo y arquitectura en las Sierra de Albartacin, Teruel, 1993 pp. 58-59. 
gitud, algo a tener muy en cuenta en una zona, la del valle del Ebro y sus afluentes meridionales, en la que escasea la madera ${ }^{7}$. Este sistema de cubierta es práctico, sencillo y económico, ventajas que explican su amplia extensión en el espacio y en el tiempo; probablemente por ello no se vio la necesidad de emplear otro, si el utilizado hasta entonces se adaptaba perfectamente a las necesidades que se creaban.

Las techumbres sobre arcos diafragma, a dos aguas o planas, son una tipología tradicional de los países de la Corona de Aragón en la Baja Edad Media. No sólo hicieron fortuna en los edificios religiosos, sino también en la arquitectura civil; sin olvidar los dormitorios y dependencias de los monasterios cistercienses, cuya influencia fue decisiva en la difusión e implantación de esta tipología. Hay numerosos ejemplos en la zona del levante español, en la que hubo resistencia a emplear la bóveda de crucería en las iglesias menores durante gran parte del siglo XIII, siendo éste un sistema que prevaleció hasta el siglo $X V^{8}$.

Esta estructura gótica de techumbre a dos aguas sobre arcos diafragma se podía enriquecer con la colocación de unos paneles a modo de falso almizate $^{9}$, recordando así formalmente a las de par y nudillo. Esto podría ser debido también a un interés por imitar las ricas techumbres almohades, haciéndolo de este modo formalmente pero sin llegar a adoptar realmente su estructura.

En la provincia de Teruel se localiza una de las más bellas techumbres sobre arcos diafragma con falso almizate; se trata de la que cubre la ermita

7. Véase Gonzalo BORRÁs, El arte mudéjar en Teruel..., p. 17 y Arte mudéjar aragonés, Zaragoza, 1978 , p. 208. Otras obras importadas a Aragón, que tampoco tuvieron eco posterior, son las techumbres ochavadas construidas bajo el mecenazgo del arzobispo don Lope Fernández de Luna en el castillo de Mesones de Isuela y en la Seo de Zaragoza, ambas datadas hacia 1370. La poca fortuna de estas tipologías importadas almohades o nazaríes puede ser un indicio del peso que tenía la tradición en este territorio, ya fuera gótica o taifal, lo que pudo incidir en que no se viera la necesidad de adoptar estructuras más evolucionadas.

8. Sobre armaduras de madera a dos aguas, véase Leopoldo TORRES BALBÁs, «Naves de edificios anteriores al siglo XIII cubiertas con armaduras de madera sobre arcos transversales», Archivo Español de Arte, n० 126, tomo XXXII, 1959, pp. 109-119 y «Naves cubiertas con armadura de madera sobre arcos perpiaños a partir del siglo XIII», Archivo Español de Arte, n" 129, tomo XXXIII, 1960, pp. 19-43. Véase también Cristóbal GuITART, «Un grupo de iglesias protogóticas en la 'Tierra Nueva' de Aragón», Seminario de Arte Aragonés, XXV-XXVI, 1978, pp. 5-45 y Arquitectura gótica en Aragón, Zaragoza, 1978, especialmente pp. 34-40.

9. Torres Balbás ya apunta que, además de ser una ventaja para la estabilidad, se cubría así la parte más elevada en edificios de mayor importancia; Carmen Fraga incide en este aspecto y apunta que los mudéjares incorporaron novedades por lo que respecta a la decoración en las techumbres sobre arcos transversales, y señala como meramente ornamental el tablero decorado que se colocaria a modo de estrecho almizate. Cfr. Leopoldo TORRES BALBÁs, «La techumbre mudéjar de la iglesia de Godella (Valencia)», Al-Andalus, vol. XX, 1955, pp. 196206; Carmen FraGA, «Carpintería mudéjar: sistema y técnicas de trabajo», Actas del III Simposio Internacional de Mudejarismo, Teruel, 20-22 de septiembre de 1984, Teruel, 1986, pp. 473-490. 
de la Virgen de la Fuente, en Peñarroya de Tastavins. Esta construcción, que perteneció a la Orden militar de Calatrava, puede datarse en la segunda mitad del siglo XIV ${ }^{10}$. Gonzalo Borrás incide en el hecho de que se utiliza aquí una tipología tradicional de la Corona de Aragón, pero destacando que "se evidencia una perfecta adecuación de las técnicas más elementales y sencillas de la carpintería mudéjar a las estructuras de la arquitectura gótica levantina" 11 .

La ermita se divide en cinco tramos mediante cuatro arcos diafragma apuntados; los dos primeros tramos (si contamos a partir del testero) tienen una estructura simple de cubierta a dos aguas sobre arcos diafragma, mientras que los tres últimos añaden a esa estructura un panel a modo de falso almizate. Las vigas maestras o jácenas apean sobre unos canes en forma de proa de nave. La techumbre presenta decoración pintada y tallada de gran riqueza, de forma que los elementos góticos y los de tradición musulmana se han integrado perfectamente para ofrecer un conjunto de gran interés, tanto estructural como decorativamente.

El cuarto tramo es el más interesante; en él las jaldetas no son visibles y las jácenas lo dividen en siete secciones, cada una de las cuales está rodeada por una serie de mensulillas en forma de proa de nave que cierran el espacio. Sobre esta estructura se sitúan unos paneles decorados; los laterales presentan lazos de seis pintados, mientras que el central muestra una decoración ataujerada en forma de lazo de cuatro octogonal, con cupulillas gallonadas y cruces de Calatrava, todo presidido por un enorme escudo de la citada orden. Se completa la decoración de este tramo con decoración geométrica tallada y decoración pintada, figurada, vegetal y heráldica, tal y como sucede en el resto de la techumbre. En los dos primeros tramos llaman la atención unas mensulillas, similares a las que rodean los segmentos de este cuarto tramo, localizadas a ambos lados de las jácenas superiores, aparentando soportar las jaldetas en su zona superior.

A modo de arrocabe corren bajo el estribo unas tablas, de las que sólo queda una original en el lado sur del segundo tramo; están decoradas con unos caballeros, en disposición y estilo idénticos a los que presentan unas tablas conservadas en el Museo Nacional de Arte de Cataluña ${ }^{12}$. Estas tablas están pintadas con motivos de caballeros, escuderos y galeras; posiblemente en un origen estuvieron unidas, formando una tabla dividida en tres esce-

10. Cfr. Manuel Siurana, La arquitectura gótica religiosa del Bajo Aragón turolense, Teruel, 1982, especialmente pp. 105-115; este autor nos informa de que la ermita en 1349 estaba en proceso de construcción y en 1369, como mucho, estaba acabada.

11. Gonzalo BORRÁs, El arte mudéjar en Teruel..., p. 61.

12. Concretamente las tablas 15.839 y 24.116 , que ya son conocidas por otras publicaciones; $\mathrm{cfr}$ Arthur BYNE y Mildred STAPLEY, Decorated wooden ceilings in Spain, New York-London, 1920, p. 18 y lám. V; Santiago SEBASTIÁN, op. cit.; id., 750 Aniversari entorn a Jaume I (Catálogo de la Exposición), Valencia, 1989. 
nas. Sus medidas coinciden con las de la zona del arrocabe del lado sur del primer tramo, y en mi opinión ésta sería su localización original. Estas tablas parecen estar relacionadas estilísticamente con las pinturas murales del castillo de Alcañiz, aspecto fácil de comprender si se tiene en cuenta que ambas obras se hicieron para la orden de Calatrava, pudiendo estar realizadas incluso por el mismo grupo de artistas. Las pinturas murales del castillo se sitúan a mediados del siglo XIV, fecha próxima también a la realización de la techumbre de Peñarroya de Tastavins ${ }^{13}$.

Esta techumbre presenta semejanzas con otras obras de la zona levantina, tanto en el aspecto estructural como en el decorativo; semejanzas que no han de extrañarnos ya que las relaciones artísticas entre los territorios de la Corona de Aragón eran muy intensos en la Edad Media. Además, el Bajo Aragón (zona en la que se sitúa esta ermita) está muy relacionada artísticamente con la del levante, como ya ha sido puesto de manifiesto en varios estudios. Por lo que respecta a la decoración pintada de vigas y canes, las mayores semejanzas las encontramos con obras de la zona de Montblanc (Tarragona). Estructuralmente guarda muchas similitudes con la techumbre que cubre la capilla del Cristo de la Paz de Godella (Valencia), datada a finales del siglo XIV o inicios del XV, y que presenta también un falso almizate, rodeado de una doble fila de canecillos ${ }^{14}$.

Techumbres a dos aguas sobre arcos diafragma, góticas y más sencillas, son las de las ermitas de la Virgen del Consuelo de Camañas y la de Santa Quiteria de Argente; son las únicas conocidas en la provincia de Teruel de época medieval que están decoradas, entre las muchas que debieron de construirse. Como ejemplo podemos citar la de la parroquial de Mosqueruela: los

13. Véase Jordi ROVIRA I PORT y Ángeles CASANOVAS I ROMEU, «El complejo pictórico del castillo de Alcañiz», en José Antonio BenAvente (ed.), El Castillo de Alcañiz, Taller de Arqueología de Alcañiz, Instituto de Estudios Turolenses, 1995, pp. 369-426.

14. Sobre la techumbre de Godella, véase Leopoldo TORRES BALBÁs, op. cit. en la nota 8, Asunción AlEjos, "Carpintería mudéjar en una iglesia valenciana. Aproximación al estudio de la capilla del Cristo de La Paz de Godella», Actas del II Simposio Intenacional de Mudejarismo: Arte. Teruel, 19-21 de noviembre de 1981, Teruel, 1982, pp. 261-271.

Sobre las iglesias del Campo de Tarragona y Conca de Barbarà, véase Enma Liaño, Contribución al estudio del gótico en Tarragona, Tarragona, 1976, en el que estudia las iglesias en torno a los núcleos de Montblanc y Selva del Campo, datadas en torno a finales del siglo XIII y principios del siglo XIV.

Por lo que se refiere a las relaciones del Bajo Aragón con la zona levantina, Gonzalo BorRÁs, "Algunas iglesias góticas del Bajo Aragón», Estudios de Edad Media de la Corona de Aragón, volumen $X, 1975$, pp. 603-620, opina que el gótico bajoaragonés hay que adscribirlo a la zona del gótico levantino, tanto por sus características como por su localización geográfica y de apogeo; Manuel SiURANA, op. cit., ya puso de relieve que el gótico bajoaragonés estaba íntimamente ligado al de Cataluña, Valencia y Baleares, destacando que desde el punto de vista estilístico existe una fuerte relación del núcleo gótico del Bajo Aragón turolense con el levantino en general y con el de la Conca del Barbarà y Tarragona en especial (relaciones que pueden llevarse también al contexto de las techumbres de madera, como vemos). 
restos que de ella quedan, especialemte una viga con decoración pintada, han llevado a José Francisco Casabona a suponer que formarían parte de la techumbre de madera sobre arcos diafragma de la iglesia de fines del siglo $X V^{15}$. Estos tres ejemplos turolenses se pueden relacionar con obras levantinas, especialmente de la zona tarraconense en torno a Montblanc, tal y como hemos visto que sucedía con la techumbre de Peñarroya de Tastavins.

Las ermitas de Argente y Camañas, poblaciones éstas muy próximas geográficamente, se pueden englobar dentro de las iglesias góticas de tipo rural, que suelen ser de difícil datación. En la primera se cubren con techumbre de madera sus cuatro tramos y el ábside, éste mediante una estructura en forma de medio cono. Las jácenas apoyan en unos canes tallados en nacela y presenta únicamente decoración pintada a base de sencillos motivos geométricos, heráldicos y vegetales. Pero, curiosamente, la tablazón del ábside se decora con unas bellas figuras humanas (pinturas que parecen estar descolocadas y que no encajan muy bien entre los listones) que podrían datarse a mediados del siglo XIII.

En la ermita de Camañas son los dos tramos de que consta la construcción los que se cubren con techumbre de madera a dos aguas, quizás de una fecha en torno al 1300. Sólo las dos jácenas superiores apoyan en canes, a los que se les ha rematado las esquinas y en uno de los cuales se ha conservado decoración vegetal pintada. Los papos de las vigas superiores están también decorados, a base de círculos enlazados que encierran decoración animal en el primer tramo y únicamente geométrica en el segundo. Los laterales de ambas jácenas se han dividido en segmentos, donde se localiza una decoración figurada de estilo gótico lineal, con caballeros, faenas agrícolas, animales fantásticos, etc.

Ya he comentado cómo sobre arcos diafragma también pueden apear estructuras planas o alfarjes; un ejemplo de este tipo es el que se localiza en la planta noble de la torre del homenaje del Castillo calatravo de Alcañiz, sala ricamente adornada con pinturas murales góticas. Se trata de un alfarje de sencilla estructura y decoración, que sirve de forjado de suelo al piso superior; cada uno de los tres tramos se divide mediante vigas en calles y a su vez éstas en segmentos por medio de unos listones. La decoración pintada es heráldica, geométrica y vegetal estilizada, destacando en el conjunto las rosetas que decoran cada segmento. Los estudiosos de este castillo ${ }^{16}$ sitúan las

15. José Francisco CASABONA, en su tesis de licenciatura inédita sobre la iglesia parroquial de Mosqueruela (leída en 1986), insiste en las relaciones del gótico bajoaragonés con el de la zona levantina al estudiar los paralelismos de la construcción medieval de 1400, que se cubriría con techumbre de madera sobre arcos diafragma; de este trabajo se publicó un resumen, «La iglesia parroquial de Mosqueruela. Estudio artístico», Restimenes de memorias de licenciatura. Curso 1985-86, Zaragoza, pp. 297-301.

16. Ver nota 13. 
pinturas murales de esta sala a mediados del siglo XIV; esta fecha, o quizás una un poco anterior, fácilmente podría ser también la de la construcción de la techumbre. La conservación de parte de este alfarje nos hace recordar la multitud de ocasiones en que este sistema de cubrición se empleó en las salas de castillos y palacios, cubiertas hoy desaparecidas (como, por ejemplo, las de los castillos turolenses de Valderrobres y Albalate del Arzobispo).

En otras construcciones civiles también se emplearon techos planos para cubrir distintas estancias, como sucede en una del Ayuntamiento de Cantavieja. Se trata de un alfarje ya tardío que se divide en trece tramos por medio de unas jácenas que apean en ménsulas de estilo gótico. La única decoración que presenta actualmente es el agramilado de sus vigas y la talla de los canes, que son de un tipo muy corriente en Aragón y levante en la segunda mitad del siglo XV y primera del XVI.

Otro alfarje, estructura dominante entre las techumbres mudéjares aragonesas, es el conocido como de la Casa del Judío, de origen turolense pero hoy localizado en Norteamérica. Esta obra, que procedería del alcázar real de Alfonso V, es conocida por los estudios de Miguel Merino ${ }^{17}$, autor que la data hacia 1425. En su disposición original dos jácenas dividían la techumbre en tres secciones, rodeadas por canecillos de proa. Esta estructura posee gran semejanza con la del coro alto de la iglesia de Santa María de Maluenda -situada en la zona de Calatayud (Zaragoza) y datado hacia 1400- y recuerda también las soluciones del cuarto tramo de la techumbre de Peñarroya de Tastavins, del almizate de la techumbre de Godella (Valencia) o de otras techumbres de la zona de Calatayud (concretamente los coros altos de las iglesias de la Virgen de Tobed y de San Félix de Torralba de Ribota).

Que esta solución estructural-decorativa, consistente en rodear secciones o tramos con canecillos de proa, se repita en distintas techumbres me induce a pensar que existía un sustrato común que las alimentaba; en este sentido no podemos olvidar que los alfarjes mudéjares son estructuras que derivan de modelos musulmanes, entre los que podríamos citar las desaparecidas techumbres del palacio islámico de la Aljafería, estudiadas por Bernabé Cabañero y Carmelo Lasa. Estos autores concluyen que la alcoba oeste del Salón del Trono estaba cubierta originariamente por un alfarje, sustentado por un friso de ménsulas y cobijas de yeso; para reconstruir la parte de madera se basan en la techumbre del coro alto de la Virgen de Tobed, que consideran semejante en cuanto a su estructura al alfarje del palacio taifal, del que derivaría ${ }^{18}$. Considero que es éste un interesante tema, sobre el que aún queda mucho por investigar.

17. Véanse sus trabajos citados en la nota 2.

18. Bernabé CABAÑero y Carmelo LASA, «Las techumbres islámicas del palacio de la Aljafería. Fuentes para su estudio", Artigrama, 10, 1993, pp. 79-120. 
Para concluir sólo querría llamar la atención sobre el hecho de que, como resultado de su particular evolución al margen de la carpintería almohade, la carpintería mudéjar aragonesa fue adquiriendo una personalidad propia en la que tradición gótica y herencia taifal se fundieron para dar como resultado unas obras que podrían caracterizarse por su sencillez (si se comparan con las que evolucionaron a partir del arte almohade o nazarí), pero que no por ello carecen de interés ${ }^{19}$.

19. Cfr. Gonzalo Borrás, El arte mudéjar en Teruel..., p. 61. 


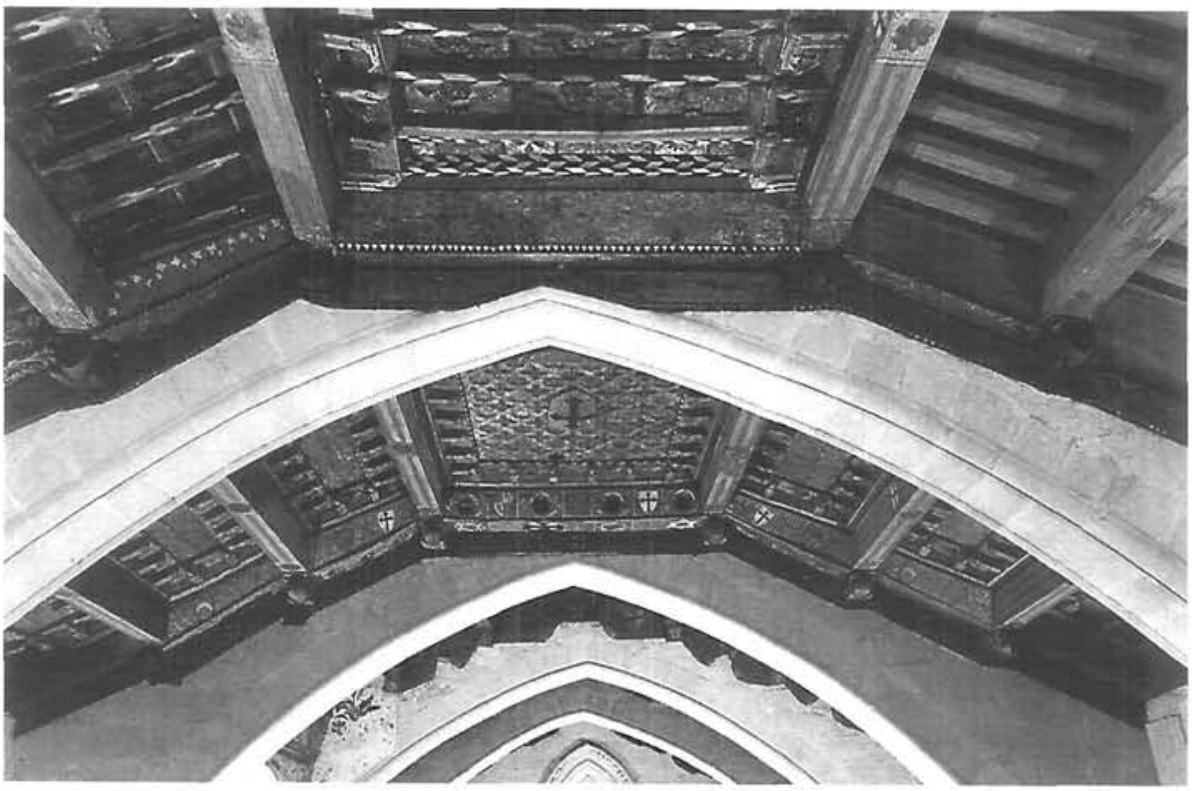

Fig. 1. Techumbre de la ermita de la Virgen de la Fuente de Peñarroya de Tastavins (Teruel).

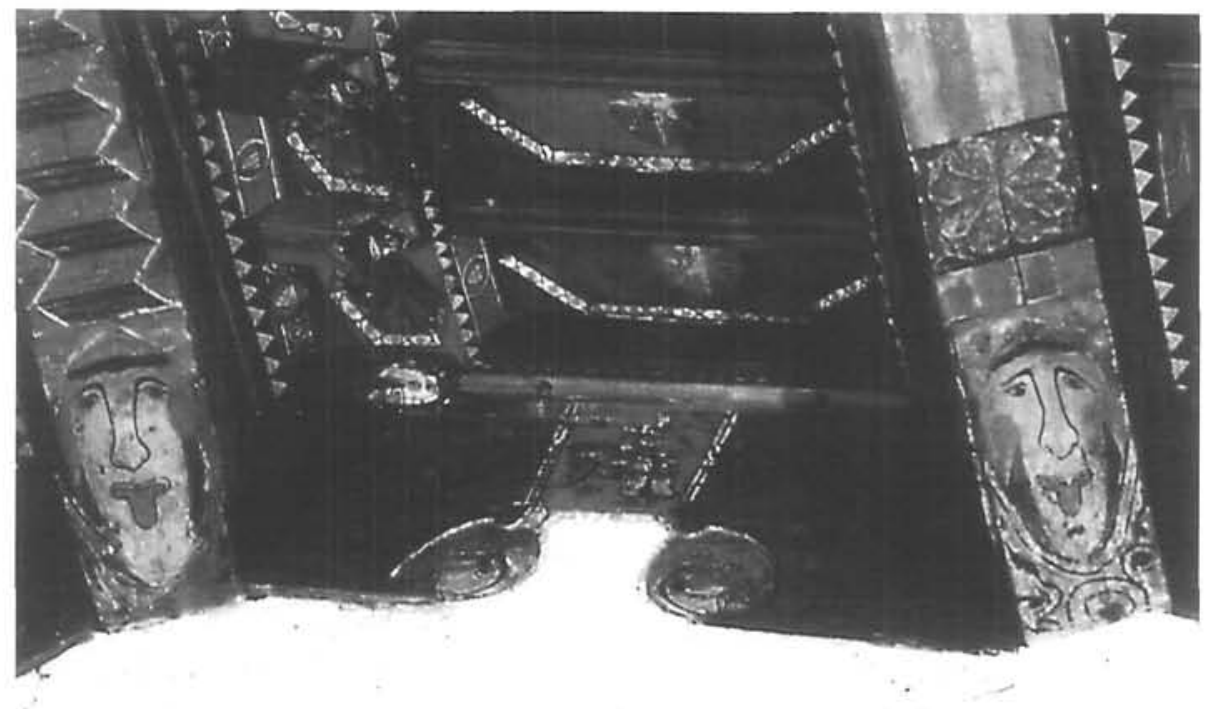

Fig. 2. Detalle del segundo tramo de la techumbre de la ermita de la Virgen de la Fuente de Peñarroya de Tastavins (Teruel). 


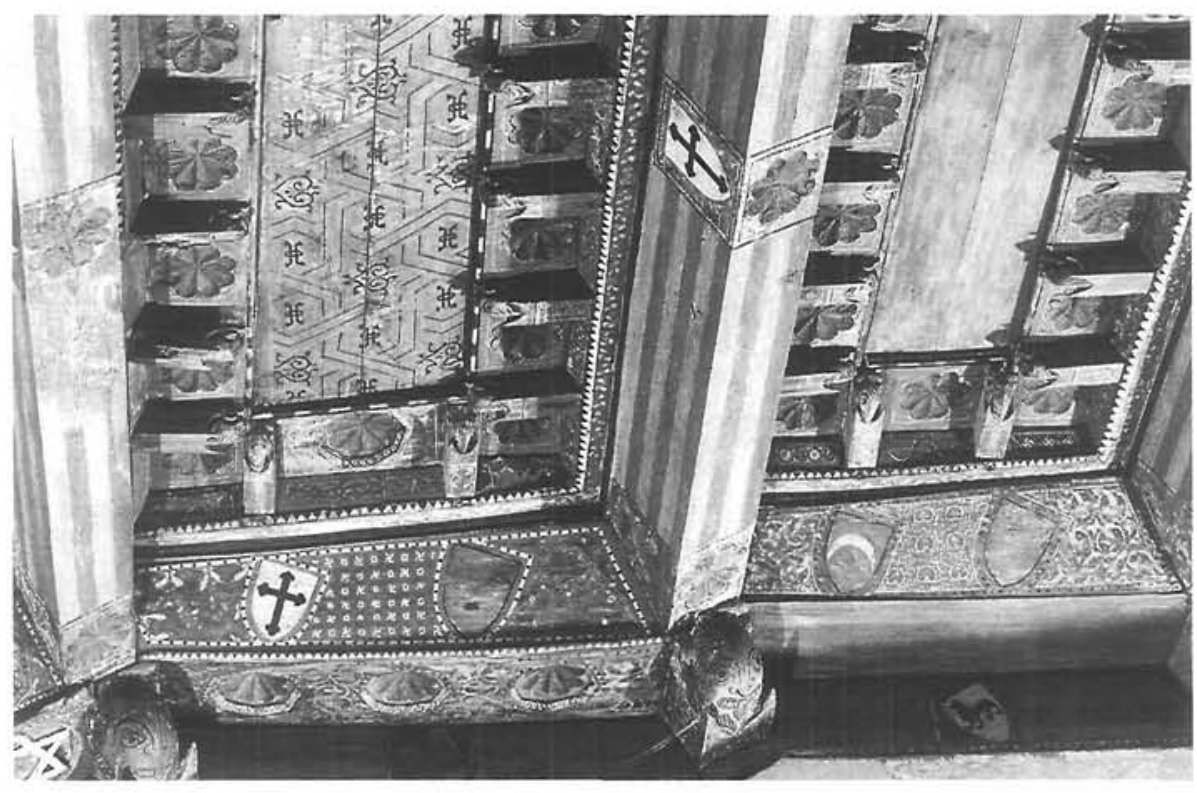

Fig. 3. Detalle del cuarto tramo de la techumbre de la ermita de la Virgen de la Fuente de Peñarroya de Tastavins (Teruel).

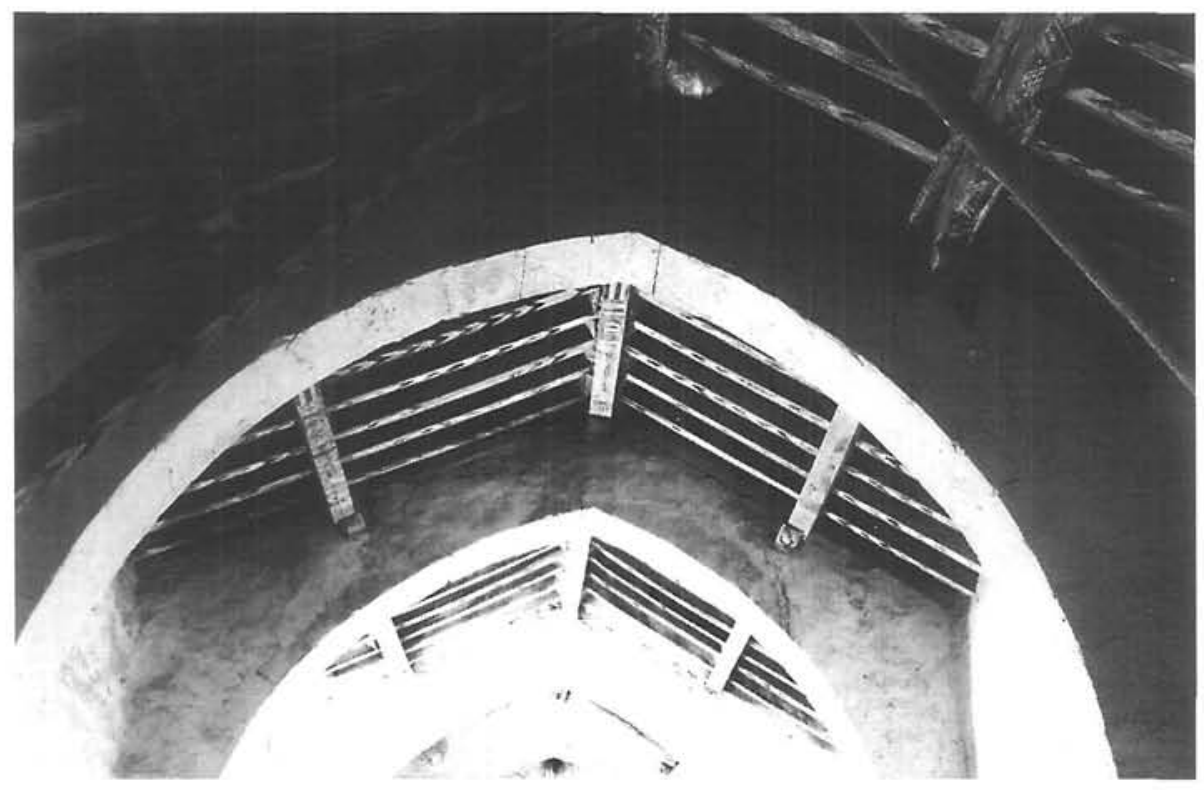

Fig. 4. Techumbre de la ermita de Santa Quiteria de Argente (Teruel). 


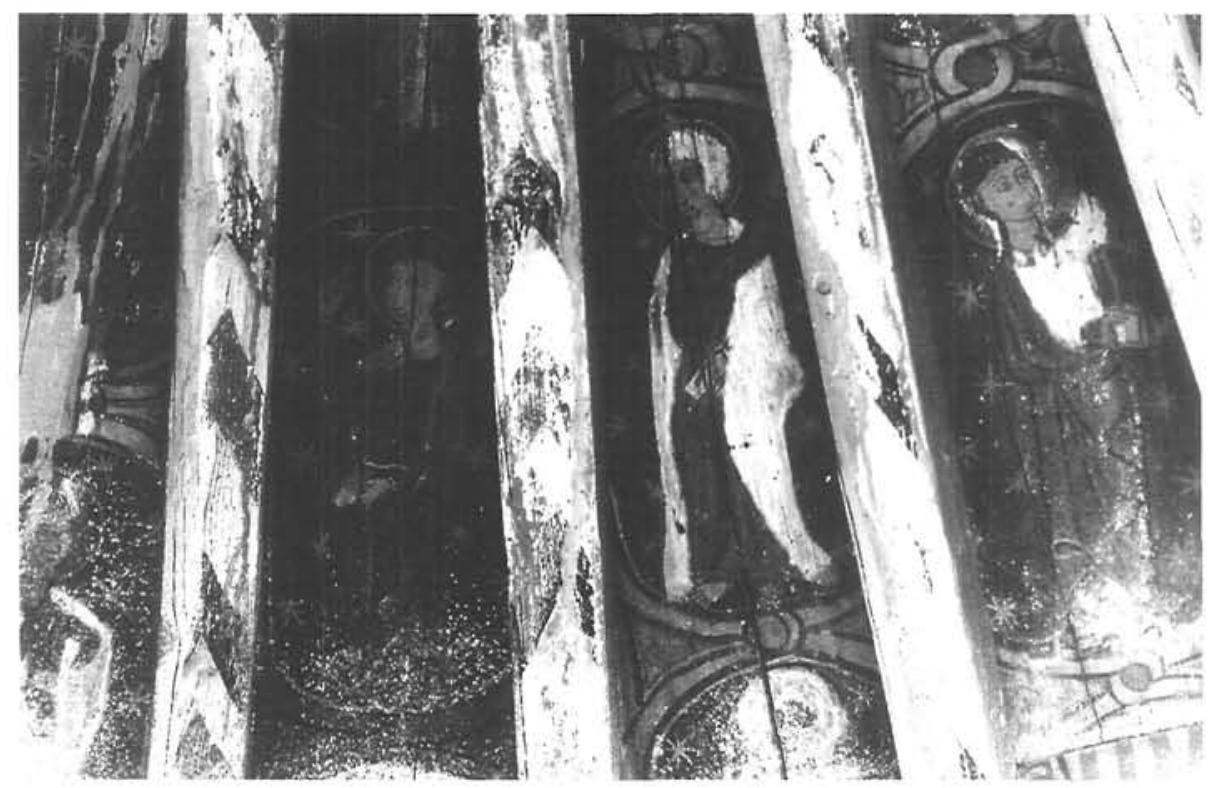

Fig. 5. Detalle del ábside de la techumbre de la ermita de Santa Quiteria de Argente (Teruel).

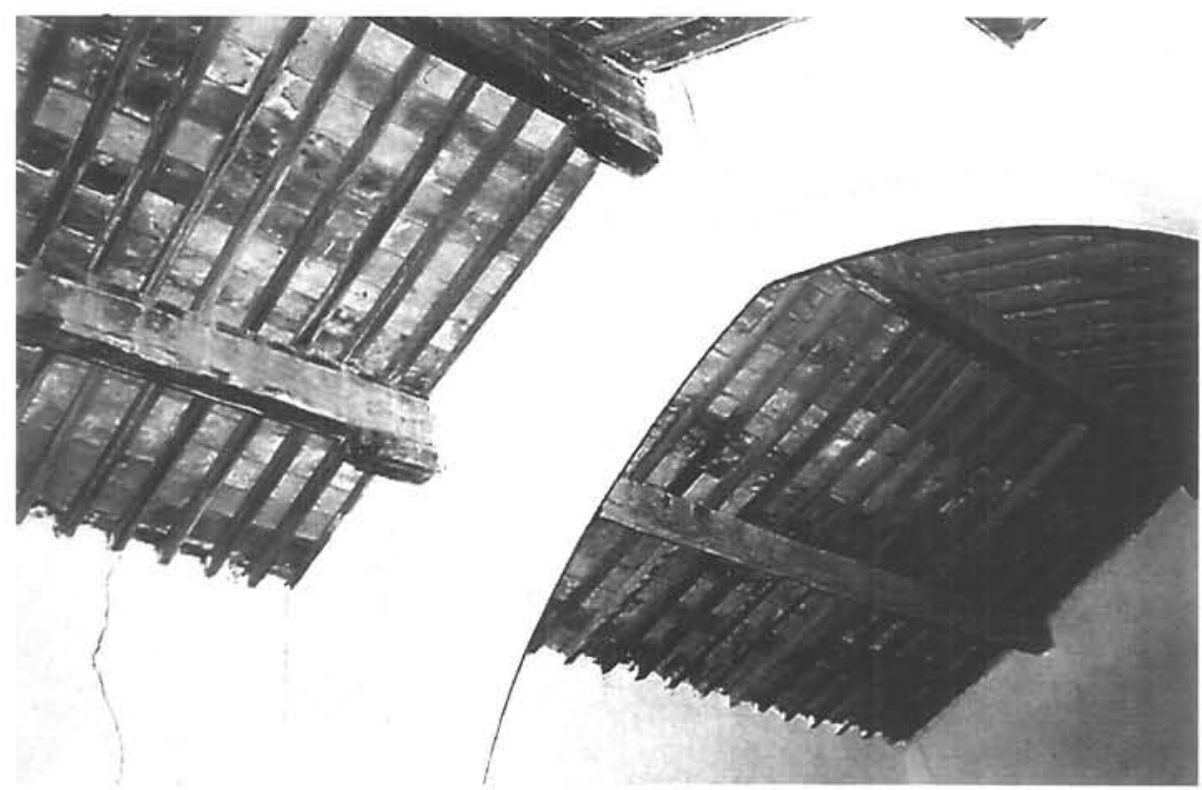

Fig. 6. Techumbre de la ermita de la Virgen del Consuelo de Camañas (Teruel). 


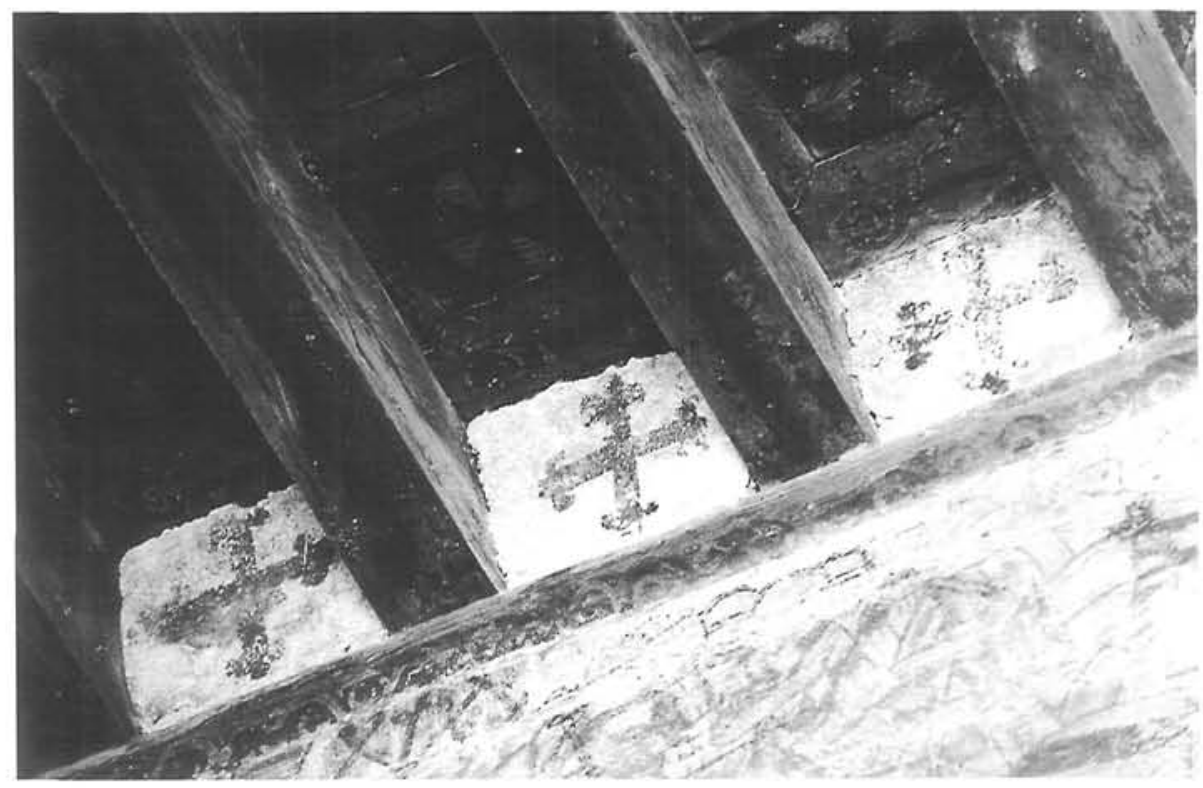

Fig. 7. Detalle de la techumbre del Castillo de Alcañiz (Teruel).

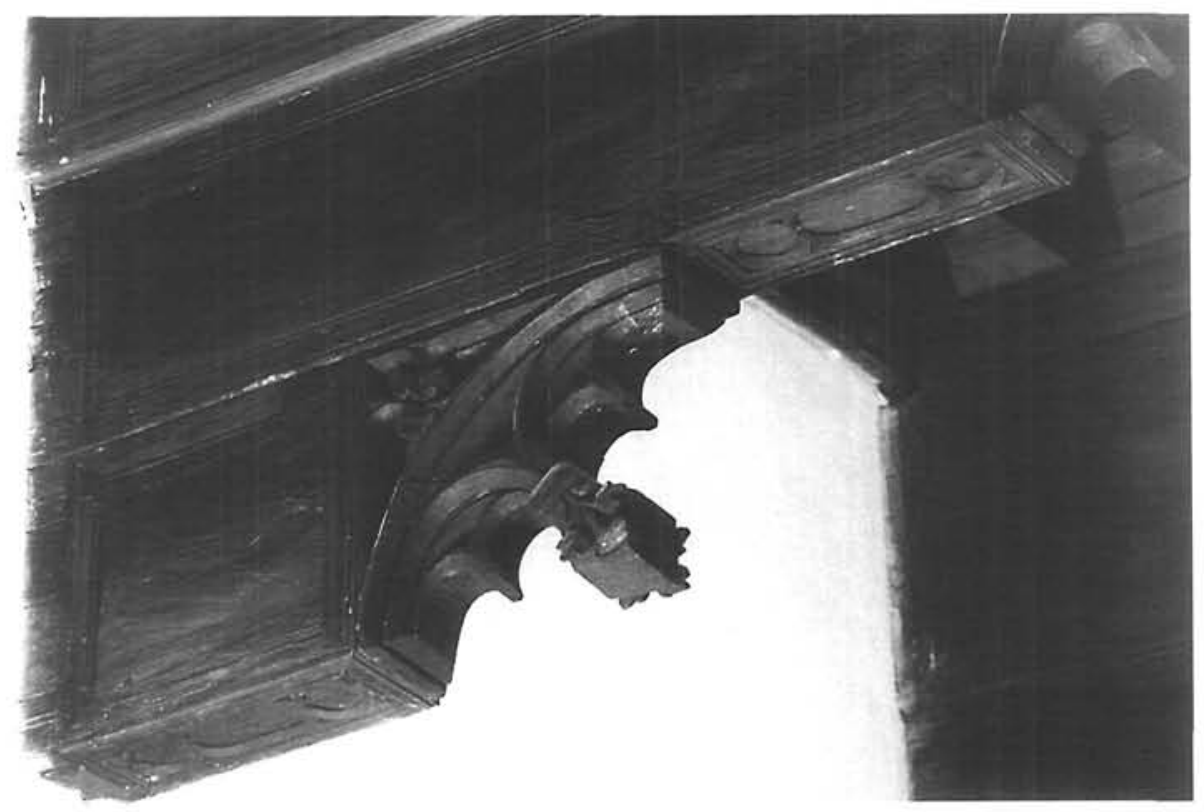

Fig. 8. Detalle de la techumbre del Ayuntamiento de Cantavieja (Teruel). 